\title{
Transcriptional response of Mycoplasma genitalium to osmotic stress
}

\begin{abstract}
Correspondence
Joel B. Baseman

baseman@uthscsa.edu
\end{abstract}

Received 21 July 2010

Revised 26 October 2010

Accepted 2 November 2010

\author{
Wenbo Zhang and Joel B. Baseman
}

Department of Microbiology and Immunology, The University of Texas Health Science Center at San Antonio, 7703 Floyd Curl Drive, San Antonio, TX 78229, USA

\begin{abstract}
Mycoplasma genitalium is the causative agent of non-gonococcal, chlamydia-negative urethritis in men and has been linked to reproductive tract disease syndromes in women. As with other mycoplasmas, $M$. genitalium lacks many regulatory genes because of its streamlined genome and total dependence on a parasitic existence. Therefore, it is important to understand how gene regulation occurs in $M$. genitalium, particularly in response to environmental signals likely to be encountered in vivo. In this study, we developed an oligonucleotide-based microarray to investigate transcriptional changes in M. genitalium following osmotic shock. Using a physiologically relevant osmolarity condition ( $0.3 \mathrm{M}$ sodium chloride), we identified 39 upregulated and 72 downregulated genes. Of the upregulated genes, 21 were of unknown function and 15 encoded membrane-associated proteins. The majority of downregulated genes encoded enzymes involved in energy metabolism and components of the protein translation process. These data provide insights into the in vivo response of $M$. genitalium to hyperosmolarity conditions and identify candidate genes that may contribute to mycoplasma survival in the urogenital tract.
\end{abstract}

\section{INTRODUCTION}

Mycoplasma genitalium is an important sexually transmitted pathogen that causes non-gonococcal, chlamydianegative urethritis in men and reproductive tract disease syndromes in women (Baseman \& Tully, 1997; Jensen, 2004). It is considered to be a parasite of the urogenital tract that colonizes the surface of epithelial cells through multiple adhesin-mediated cytadherence mechanisms (Alvarez et al., 2003; Baseman, 1993). Although M. genitalium is often regarded as an extracellular pathogen, it has been reported to invade host cells and establish longterm persistence (Baseman et al., 1995; Blaylock et al., 2004; Ueno et al., 2008). This observation may account for the chronic infections associated with M. genitalium, despite extensive antibiotic therapies and an intact and functional host immune system.

M. genitalium represents the smallest known self-replicating micro-organism that can be passaged in artificial medium. Also, M. genitalium has a streamlined genome (0.58 Mbp) containing only 482 protein-encoding genes,

Abbreviations: $Q$ value, false discovery rate; $R T$, reverse transcriptase.

Microarray data have been submitted to the Gene Expression Omnibus database with the accession number GSE22661.

A supplementary figure, showing an expression map of $M$. genitalium in the presence of $0.3 \mathrm{M} \mathrm{NaCl}$, and a supplementary table, listing $M$. genitalium genes preferentially upregulated in the presence of $0.2 \mathrm{M}$ $\mathrm{NaCl}$, are available with the online version of this paper. which approximates the minimal gene set essential to sustain independent life (Fraser et al., 1995; Glass et al., 2006). Despite the limitation of genome content, $M$. genitalium must be able to adapt to changing in vivo environmental conditions given its intimate interaction with host cells. Unfortunately, little information is available concerning the mechanisms by which $M$. genitalium regulates gene expression. Transcriptional control in mycoplasmas appears unique, as these prokaryotes possess relatively few regulatory factors compared with other bacteria, possibly due to reduced genome size (Himmelreich et al., 1997) and their successful adaptation to host environments (Weiner et al., 2000). The availability of DNA microarrays facilitates the study of transcriptional regulation in mycoplasmas by examining global transcriptional changes. The first evidence of differential expression of genes in pathogenic mycoplasmas was revealed using microarrays in Mycoplasma pneumoniae during heat shock (Weiner et al., 2003). Later, additional Mycoplasma species were tested under conditions of heat shock (Madsen et al., 2006a), oxidative stress (Schafer et al., 2007), depletion of iron (Madsen et al., 2006b), association with eukaryotic cells (Cecchini et al., 2007) or during infection (Madsen et al., 2008). To date, only a subset of conserved heat-shock genes of M. genitalium has been shown by macroarray to be differentially expressed in response to elevated temperature (Musatovova et al., 2006) and no global transcriptional analysis has been performed on this smallest self-replicating prokaryote. 
In this study, we developed an oligonucleotide-based microarray specific for $M$. genitalium, which represents all known ORFs annotated in the genome. Utilizing this microarray, we examined the transcriptional changes of $M$. genitalium in response to osmotic stress, an environmental change that $M$. genitalium encounters in the human urinary tract where osmotic pressure fluctuations are created by passing and residual urine. With this approach, we identified a set of genes that displayed differential expression under osmotic stress.

\section{METHODS}

Mycoplasma strain and growth. M. genitalium type strain G37 was routinely grown in Spiroplasma (SP)-4 medium at $37{ }^{\circ} \mathrm{C}$. To assess the growth of $M$. genitalium in the presence of various concentrations of $\mathrm{NaCl}$, we measured the incorporation of ${ }^{14} \mathrm{C}$-labelled lysine into protein over time. Equal numbers of strain G37 cells $\left(1 \times 10^{6}\right.$ colour change units) were inoculated into three 12 -well plates (1 ml SP-4 medium per well). After incubation at $37^{\circ} \mathrm{C}$ for $60 \mathrm{~h}, \mathrm{NaCl}$ was added to final concentrations of $0.1,0.2$ and $0.3 \mathrm{M}$ to triplicate wells of each plate. The remaining three wells were untreated and served as controls. Then, $0.1 \mu \mathrm{Ci}(0.37 \mathrm{kBq}) \mathrm{L}-\left[\mathrm{U}_{-}{ }^{14} \mathrm{C}\right]$-lysine (Amersham) was added to each well, and cultures were reincubated at $37^{\circ} \mathrm{C}$. At each time point $(72,96$ and $120 \mathrm{~h})$, one plate was processed by aspirating the spent medium, washing wells once with PBS, lysing mycoplasma cells with $0.5 \mathrm{ml} 10 \%$ SDS, and determining radioactivity values by scintillation counting.

Microarray design. An oligonucleotide-based microarray specific for M. genitalium was designed and synthesized by Qiagen Operon. Oligonucleotides (70-mers) representing 482 putative ORFs of type strain G37 (ATCC 33530) were printed on slides by Microarrays Inc. In addition, 24 empty spots were included as negative controls. All spots were printed in triplicate on one slide to improve the reproducibility of array data.

Experimental design. To examine the effects of hyperosmolarity on M. genitalium transcription, four $50 \mathrm{ml}$ cultures of strain $\mathrm{G} 37$ in $75 \mathrm{~cm}^{2}$ tissue culture flasks (Corning) were grown to exponential phase, as determined by medium colour change and colony density. Then, $\mathrm{NaCl}$ was added to three flasks to achieve final concentrations of $0.1,0.2$ and $0.3 \mathrm{M}$. Parallel cultures of M. genitalium in the absence of $\mathrm{NaCl}$ served as controls. All cultures were incubated for $1 \mathrm{~h}$ at $37{ }^{\circ} \mathrm{C}$ prior to RNA extraction. Experiments were repeated six times, which produced six independent RNA sample pairs from $\mathrm{NaCl}$ treated cultures and control cultures for each $\mathrm{NaCl}$ condition. Dye swap was performed on three of six RNA pairs to minimize effects caused by biased labelling efficiencies.

RNA manipulation. Tri Reagent (Sigma) was used to extract total $M$. genitalium RNA according to manufacturer's guidelines. Briefly, surface-attached $M$. genitalium cells were washed twice with ice-cold sterile PBS, and Tri Reagent ( $8 \mathrm{ml}$ per $75 \mathrm{~cm}^{2}$ flask surface) was added to lyse cells. For microarray analysis, total RNA preparations were further processed with an RNeasy mini kit (Qiagen) to remove RNAs less than $200 \mathrm{nt}$. To stabilize RNA samples, 200 units RNase inhibitor RNaseOUT (Invitrogen) was added to each RNA preparation. For real-time PCR analysis, total RNA preparations were further treated with amplification-grade DNase I (Invitrogen) to remove residual genomic DNA.

Microarray hybridization. For probe preparation, hybridization and slide washing, we followed microarray protocols (SOP no. M007 and
M008) from the Pathogen Functional Genomics Resource Center of the J. Craig Venter Institute with slight modification (http://pfgrc.jcvi. org/index.php/microarray/protocols.html). Hybridization probes were generated with a set of 482 gene-specific primers (designed and synthesized by Operon Biotechnologies) by reverse transcription of $4 \mu \mathrm{g}$ total $M$. genitalium RNA in the presence of aminoallyl-labelled dUTP (2:1 ratio of aa-dUTP : dTTP). After clean-up, the aminoallyllabelled cDNA preparations were coupled to either cyanine $(\mathrm{Cy}) 3$ or Cy5 fluorescent molecules (Amersham Biosciences). Hybridization and slide washing followed protocol SOP no. M008.

Data acquisition and analysis. Microarray slides were scanned with a GenePix 4000B microarray scanner (Axon Instruments) at $10 \mu \mathrm{m}$ resolution, and laser power was kept constant for Cy3/Cy5 scans of all slides. Photomultiplier tube (PMT) voltages were adjusted using GenePix Pro 6.0 (Axon Instruments) to obtain maximal signal intensities of each feature with a saturation of $<0.005 \%$ and count ratio close to 1.0. The resulting images were gridded and processed using GenePix Pro 6.0 to obtain the signal intensity for each spot. The data were further imported into and analysed by Acuity 4.0 (Axon Instruments). The fluorescence levels for each feature of individual slides were first normalized using the ratio-based method and a dataset was created. The relative expression level of each ORF was calculated, and the $P$-values were determined across the dataset using Student's $t$ test. Then, the $482 P$-values from the $t$ test were imported into QVALUE (Storey \& Tibshirani, 2003) and false discovery rate $(Q)$ values were computed at an estimated false discovery rate of $5 \%$. Along with $Q$ values, differentially expressed genes were identified by filtering features that were up- or downregulated more than twofold $(P<0.01)$.

Validation of microarray data by real-time PCR. Real-time PCR analysis was performed with the ABI Prism 7900 sequence detection system and SYBR green chemistry (Applied Biosystems). Primers were designed using Primer Express 2.0 (Applied Biosystems; Table 1). All primers were tested to be specific for individual genes, as indicated by a single peak after dissociation of each amplification product and a single band after agarose gel electrophoresis. Efficiencies of the target amplification and reference (endogenous control) amplification were confirmed to be equal $\left(\mathrm{R}^{2}>0.99\right)$ using five serial 10 -fold dilutions of

Table 1. Primers used in real-time PCR analysis

\begin{tabular}{|ll|}
\hline Primer & \multicolumn{1}{c|}{ Sequence $\left(\mathbf{5}^{\prime}-\mathbf{3}^{\prime}\right)$} \\
\hline MG_003F & TGCTGGTGGCACTGCTAAAA \\
MG_003R & CAACGTTTAAAATCTTTCCTCTTAAGG \\
MG_074F & CCTCTTAGTCTTTGTCTTGCTTTTCTT \\
MG_074R & GCAAACAAGCAGTGTAGGAAAATACT \\
MG_149F & TGAAAGAAAAAATATGAGTGGTTCAACTAG \\
MG_149R & AAGAGAGCTTACGTTCCTCTTTATGTTC \\
MG_151F & CACCGCTTTCAGGGTTCTG \\
MG_151R & AAAAACACGCTGCGCACTACT \\
MG_274F & TCTTCAGCTACCGGCAAGGT \\
MG_274R & CTCCTCTTCTTGTTTGGTTCTGTAGA \\
MG_275F & CACTTGCTGTTAGTGGTGTTGTTAAA \\
MG_275R & GTTAGCGCCCATCTGTTTCAACT \\
MG_278F & TGGCATGAAAACCAGAAACG \\
MG_278R & CCATGTTCCATTCAACTAGTGATAATG \\
MG_451F & AAACGTCACTATGCCCATGTTG \\
MG_451R & TGCAGCACCTGTGATCATATTTT \\
MG_454F & TTGCACAAACTGAAACTGGCA \\
MG_454R & TGAGAAAAACAACTTGCATAAGCAG \\
\hline
\end{tabular}




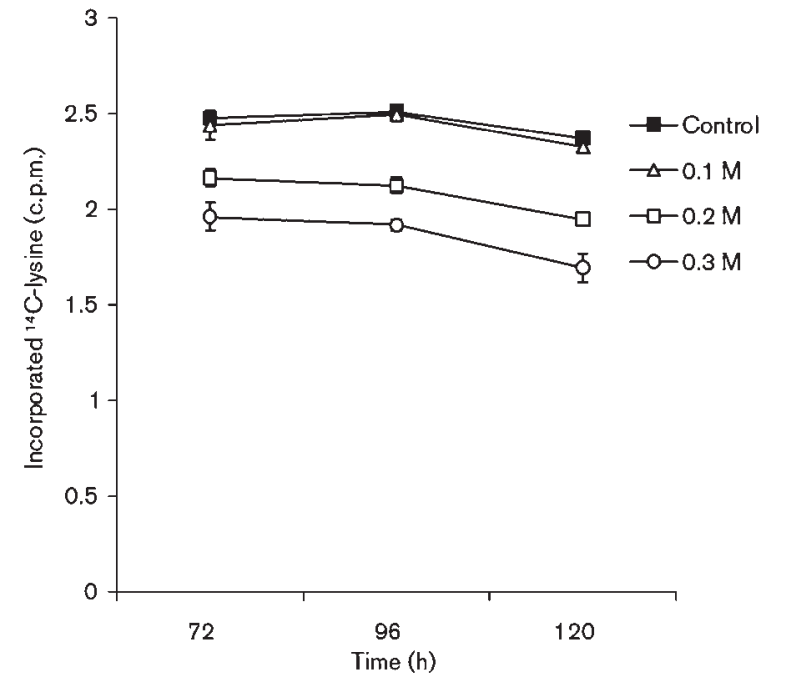

Fig. 1. Growth of M. genitalium in the presence of $\mathrm{NaCl}$. A semilogarithmic plot based upon the incorporation of ${ }^{14} \mathrm{C}$-lysine (c.p.m.) at 72,96 and $120 \mathrm{~h}$ is presented. $\mathrm{NaCl}$ and ${ }^{14} \mathrm{C}$-lysine were added to cultures after $60 \mathrm{~h}$ of growth. Thereafter, at the indicated times, mycoplasma cells were washed and lysed for scintillation counting. Error bars represent standard deviations of values obtained from three independent replicates.

M. genitalium genomic DNA $\left(10^{8}-10^{4}\right.$ copies per reaction) as templates according to User Bulletin No.2 (Applied Biosystems). To prepare the cDNA template, $1 \mu \mathrm{g}$ DNase I-treated RNA was reverse transcribed with SuperScript Reverse Transcriptase (RT) II (Invitrogen). Then, cDNA templates were diluted and mixed with SYBR green PCR master mix and corresponding primers. Also, RTnegative RNAs were included as templates to estimate the residual contamination of genomic DNA. Amplifications were carried out under default conditions provided by the manufacturer. We applied the comparative threshold cycle method to compare amounts of transcripts under different experimental conditions. The relative levels of transcripts were expressed as fold changes ( $n$-fold) compared with control values, and calculations were completed using RQ Manager 1.2 (Applied Biosystems).

Microarray data accession number. Microarray data were submitted to the Gene Expression Omnibus database under the accession number GSE22661.

\section{RESULTS}

\section{Transcriptional profiling of M. genitalium treated with hyperosmolarity conditions}

To examine the transcriptomes of $M$. genitalium in response to osmotic shock, we added $\mathrm{NaCl}$ to exponential-phase cultures of M. genitalium to final concentrations of $0.1,0.2$ and $0.3 \mathrm{M}$ and continued incubation for $1 \mathrm{~h}$. The addition of $\mathrm{NaCl}$ raised the osmotic pressure of SP-4 medium from $394 \mathrm{mOsm} \mathrm{kg}^{-1}$ to 584, 771 and $930 \mathrm{mOsm}$ $\mathrm{kg}^{-1}$, respectively, which are within the physiological range

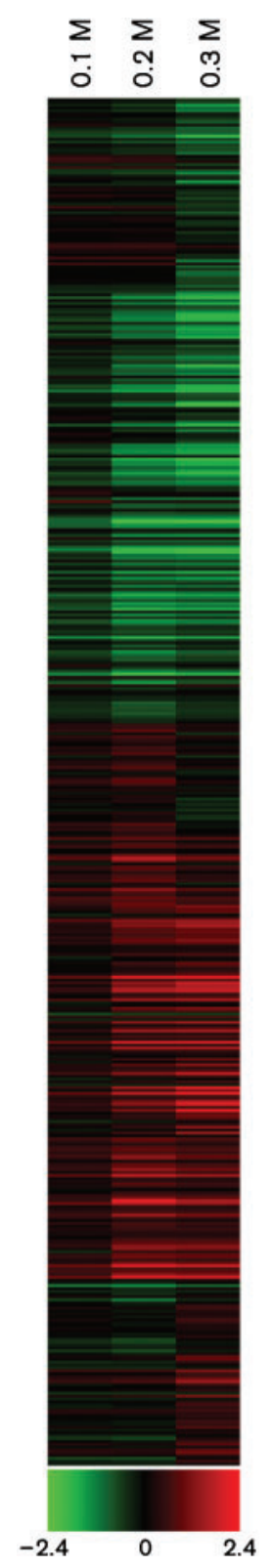

Fig. 2. Hierarchical clustering analysis of $M$. genitalium genes upon exposure to $\mathrm{NaCl}$ for $1 \mathrm{~h}$. Genes were grouped on the basis of similarity of expression patterns. Each gene is represented by a single row of coloured lines (red, induced; green, repressed). The colour scale ranges from saturated green for log ratios -2.4 and below to saturated red for log ratios 2.4 and above.

of human urine osmolarity (50-1400 $\mathrm{mOsm} \mathrm{kg}^{-1}$ ). The growth of $M$. genitalium was not affected in the presence of $0.1 \mathrm{M} \mathrm{NaCl}$, as indicated by the rate of protein synthesis (Fig. 1). At high $\mathrm{NaCl}$ concentrations $(0.2$ and $0.3 \mathrm{M}$ $\mathrm{NaCl}$ ), although $M$. genitalium protein synthesis was reduced, the viability of $M$. genitalium was not significantly affected based upon similar numbers of c.f.u. before and after each $\mathrm{NaCl}$ treatment (data not shown). 
Table 2. M. genitalium genes upregulated in the presence of $0.3 \mathrm{M} \mathrm{NaCl}$

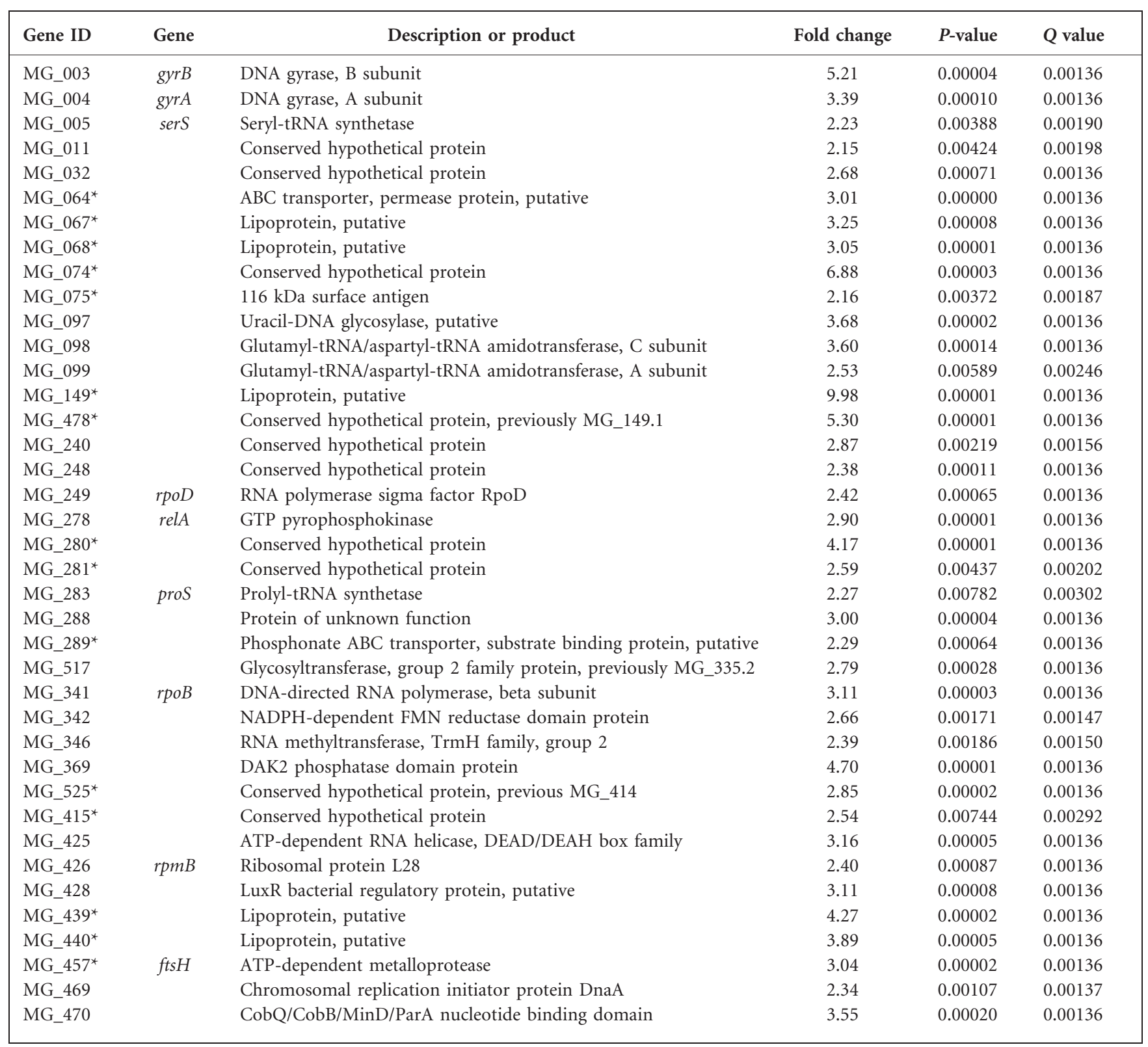

${ }^{\star}$ Genes encoding membrane proteins or membrane-associated proteins indicated by the presence of a transmembrane domain(s) in the primary amino acid sequence.

Microarray analysis was performed to compare the global transcriptome profiles of mycoplasma cultures grown in the presence of $\mathrm{NaCl}$ with control cultures. Genes exhibiting similar expression patterns under osmotic stress were grouped by hierarchical clustering analysis (Fig. 2). We observed that the expression of genes was not significantly changed when $M$. genitalium was treated with $0.1 \mathrm{M} \mathrm{NaCl}$ compared with controls. In contrast, we observed significant differential expression of genes when mycoplasma cells were exposed to $0.2 \mathrm{M}$ and $0.3 \mathrm{M} \mathrm{NaCl}$. Although some genes were preferentially expressed under $0.2 \mathrm{M} \mathrm{NaCl}$ treatment (see Supplementary Table S1, available with the online version of this paper), more genes tended to be differentially expressed under $0.3 \mathrm{M}$ $\mathrm{NaCl}$ treatment. Subsequently, differentially expressed genes under $0.3 \mathrm{M} \mathrm{NaCl}$ treatment were identified by the criteria of increases or decreases in signal greater than twofold, $P$-value less than 0.01 and an estimated false discovery rate of $5 \%$. A total of 39 upregulated genes (Table 2) and 72 downregulated genes (Table 3) met the criteria. The location of these genes and their status of expression are presented in Supplementary Fig. S1 (available with the online version of this paper). To verify that these genes were differentially expressed due to 
Table 3. M. genitalium genes downregulated in the presence of $0.3 \mathrm{M} \mathrm{NaCl}$

\begin{tabular}{|c|c|c|c|c|c|}
\hline Gene ID & Gene & Description or product & Fold change & $P$-value & $Q$ value \\
\hline MG_022 & & DNA-directed RNA polymerase, delta subunit & -2.76 & 0.00002 & 0.00136 \\
\hline MG_023 & $f b a$ & Fructose-1,6-bisphosphate aldolase, class II & -2.38 & 0.00002 & 0.00136 \\
\hline MG_061 & & Mycoplasma MFS transporter & -2.30 & 0.00029 & 0.00136 \\
\hline MG_062 & fruA & PTS system, fructose-specific IIABC component & -2.41 & 0.00013 & 0.00136 \\
\hline MG_069 & $p t s G$ & PTS system, glucose-specific IIABC component & -4.09 & 0.00002 & 0.00136 \\
\hline MG_082 & rpla & Ribosomal protein L1 & -2.60 & 0.00002 & 0.00136 \\
\hline MG_111 & pgi & Glucose-6-phosphate isomerase & -4.16 & 0.00002 & 0.00136 \\
\hline MG_112 & rpe & Ribulose-phosphate 3-epimerase & -3.55 & 0.00002 & 0.00136 \\
\hline MG_124 & $\operatorname{trx}$ & Thioredoxin & -3.23 & 0.00359 & 0.00136 \\
\hline MG_125 & & Cof-like hydrolase, putative & -2.80 & 0.00004 & 0.00136 \\
\hline MG_139 & & Metallo-beta-lactamase superfamily protein & -2.04 & 0.00475 & 0.00136 \\
\hline MG_196 & infC & Translation initiation factor IF-3 & -2.72 & 0.00056 & 0.00136 \\
\hline MG_207 & & Ser/Thr protein phosphatase family protein & -2.45 & 0.00740 & 0.00136 \\
\hline MG_227 & thyA & Thymidylate synthase & -2.06 & 0.00069 & 0.00136 \\
\hline MG_228 & $d h f R$ & Dihydrofolate reductase & -2.33 & 0.00011 & 0.00136 \\
\hline MG_229 & $n r d F$ & Ribonucleoside-diphosphate reductase, beta chain & -2.63 & 0.00002 & 0.00136 \\
\hline MG_230 & $n r d I$ & NrdI protein & -2.80 & 0.00002 & 0.00136 \\
\hline MG_231 & $n r d E$ & Ribonucleoside-diphosphate reductase, alpha chain & -3.33 & 0.00001 & 0.00136 \\
\hline MG_255 & & Conserved hypothetical protein & -2.82 & 0.00079 & 0.00136 \\
\hline MG_270 & & Lipoyltransferase/lipoate-protein ligase, putative & -2.32 & 0.00002 & 0.00136 \\
\hline MG_273 & $p d h B$ & Pyruvate dehydrogenase component E1, beta subunit & -2.11 & 0.00082 & 0.00136 \\
\hline MG_274 & $\operatorname{pdh} A$ & Pyruvate dehydrogenase component E1, alpha subunit & -2.80 & 0.00001 & 0.00136 \\
\hline MG_326 & & DegV family protein & -2.08 & 0.00169 & 0.00136 \\
\hline MG_332 & & Expressed protein of unknown function & -2.47 & 0.00003 & 0.00136 \\
\hline MG_333 & & Acyl carrier protein phosphodiesterase, putative & -4.21 & 0.00001 & 0.00136 \\
\hline MG_348 & & Lipoprotein, putative & -2.80 & 0.00002 & 0.00136 \\
\hline MG_353 & & DNA-binding protein $\mathrm{HU}$, putative & -3.47 & 0.00001 & 0.00136 \\
\hline MG_354 & & Conserved hypothetical protein & -2.16 & 0.00006 & 0.00136 \\
\hline MG_357 & $\operatorname{ack} A$ & Acetate kinase & -3.22 & 0.000001 & 0.00136 \\
\hline MG_361 & & Ribosomal protein L10 & -3.19 & 0.00003 & 0.00136 \\
\hline MG_362 & rplL & Ribosomal protein L7/L12 & -2.74 & 0.00003 & 0.00136 \\
\hline MG_363 & $\operatorname{rpm} F$ & Ribosomal protein L32 & -2.19 & 0.00064 & 0.00136 \\
\hline MG_386 & p200 & P200 protein & -2.38 & 0.00001 & 0.00136 \\
\hline MG_396 & rpiB & Ribose 5-phosphate isomerase B & -2.08 & 0.00040 & 0.00136 \\
\hline MG_398 & $\operatorname{atpC}$ & ATP synthase F1, epsilon subunit & -2.52 & 0.00013 & 0.00136 \\
\hline MG_399 & $\operatorname{atpD}$ & ATP synthase F1, beta subunit & -2.88 & 0.00001 & 0.00136 \\
\hline MG_400 & $\operatorname{atp} G$ & ATP synthase F1, gamma subunit & -2.47 & 0.00001 & 0.00136 \\
\hline MG_401 & $\operatorname{atp} A$ & ATP synthase F1, alpha subunit & -2.71 & 0.00001 & 0.00136 \\
\hline MG_402 & atpH & ATP synthase F1, delta subunit & -2.14 & 0.00001 & 0.00136 \\
\hline MG_403 & $\operatorname{atp} F$ & ATP synthase F0, B subunit & -2.97 & 0.00001 & 0.00136 \\
\hline MG_404 & $\operatorname{atp} E$ & ATP synthase F0, C subunit & -3.79 & 0.00001 & 0.00136 \\
\hline MG_405 & $\operatorname{atp} B$ & ATP synthase F0, A subunit & -3.02 & 0.00001 & 0.00136 \\
\hline MG_407 & eno & Enolase & -2.29 & 0.00002 & 0.00136 \\
\hline
\end{tabular}


Table 3. cont.

\begin{tabular}{|c|c|c|c|c|c|}
\hline Gene ID & Gene & Description or product & Fold change & $P$-value & $Q$ value \\
\hline MG_408 & $m s r A$ & Methionine-S-sulfoxide reductase & -3.09 & 0.00003 & 0.00136 \\
\hline MG_430 & gpmI & $\begin{array}{l}\text { 2,3-Bisphosphoglycerate-independent phosphoglycerate } \\
\text { mutase }\end{array}$ & -2.58 & 0.00007 & 0.00136 \\
\hline MG_431 & tpiA & Triosephosphate isomerase & -2.47 & 0.00024 & 0.00136 \\
\hline MG_432 & & Membrane protein, putative & -2.54 & 0.00158 & 0.00136 \\
\hline MG_433 & $t s f$ & Translation elongation factor Ts & -3.32 & 0.00001 & 0.00136 \\
\hline MG_444 & rpls & Ribosomal protein L19 & -2.16 & 0.00001 & 0.00136 \\
\hline MG_445 & $\operatorname{trmD}$ & tRNA (guanine-N1)-methyltransferase & -3.96 & 0.00001 & 0.00136 \\
\hline MG_446 & $r p s P$ & Ribosomal protein S16 & -3.60 & 0.00001 & 0.00136 \\
\hline MG_451 & tuf & Translation elongation factor $\mathrm{Tu}$ & -3.84 & 0.00001 & 0.00136 \\
\hline MG_452 & & Membrane protein, putative & -2.56 & 0.00002 & 0.00136 \\
\hline MG_453 & galU & UTP-glucose-1-phosphate uridylyltransferase & -2.36 & 0.00163 & 0.00136 \\
\hline MG_468.1 & & $\mathrm{ABC}$ transporter, ATP-binding protein & -2.08 & 0.00204 & 0.00136 \\
\hline
\end{tabular}

osmotic upshift rather than from salt-specific effects, sucrose was used to increase osmolarity, and similar results were obtained (data not shown).

\section{Validation of microarray data}

Real-time PCR was employed and eight genes, which exhibited highly differential expression by microarray and represented important physiological roles, were chosen to confirm microarray results. MG_151, which encodes a ribosomal protein exhibiting relatively stable expression under osmotic shock, was used as the endogenous control. The primers selected for these genes are listed in Table 1. RNA samples from two biological replicates were analysed. As shown in Fig. 3, the expression patterns of all eight genes were consistent with the microarray results, although the fold changes of these osmotically upregulated genes were lower than those observed by microarray analysis. This discrepancy could be due to variations in the expression of MG_151 expression upon osmotic shock.

\section{DISCUSSION}

Bacteria respond to stressful environmental conditions by altering the expression of genes that enhance their survival. In the case of $M$. genitalium, a cell-wall-free bacterium that colonizes the genito-urinary tract, no information was available about its transcriptional response to osmotic stress, a condition likely to be encountered in vivo. By utilizing a whole-genomic microarray, we observed differential expression of genes when $M$. genitalium was exposed to 0.2 and $0.3 \mathrm{M} \mathrm{NaCl}$ for $1 \mathrm{~h}$. In total, we identified 39 upregulated and 72 downregulated genes after $0.3 \mathrm{M} \mathrm{NaCl}$ treatment, which represents about $23 \%$ (111/482) of predicted genes encoded by the genome. The microarray data were further confirmed by selecting eight genes for real-time PCR analysis, with all genes showing consistent patterns of expression. Of 39 genes upregulated by osmotic shock, 15 genes encode membrane or membrane-associated proteins, as suggested by the presence of a transmembrane domain(s) in their primary amino acid

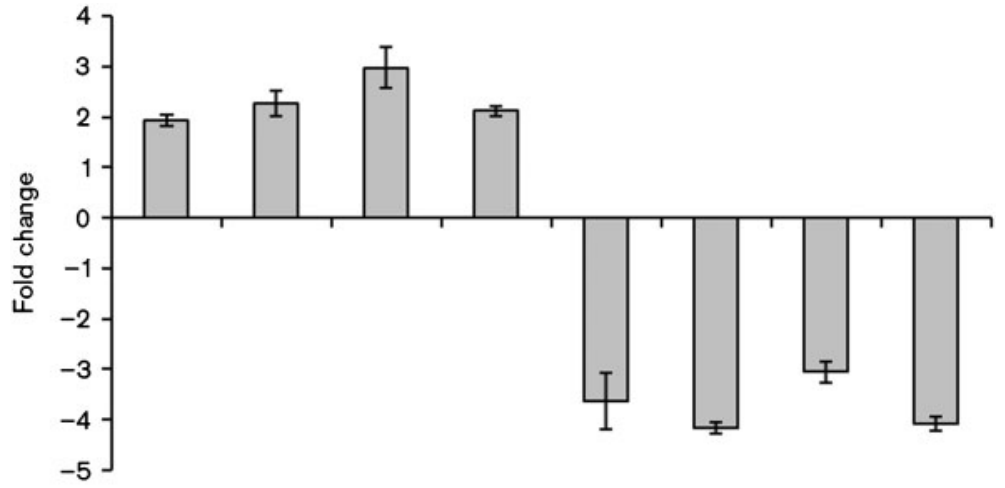

MG_003 MG_074 MG_149 MG_278 MG_274 MG_275 MG_451 MG_454
Fig. 3. Real-time PCR validation of selected M. genitalium genes differentially expressed under $0.3 \mathrm{M} \mathrm{NaCl}$. MG_151, which encodes a ribosomal protein, was used as the normalizer. Data are presented as mean $\pm \mathrm{SD}$ (error bars) from two biological replicates with each being performed in triplicate. 
sequences (Table 2). It is noteworthy that five (MG_067, MG_068, MG_149, MG_439 and MG_440) of the 21 putative lipoprotein genes encoded by the genome were significantly induced, with MG_149 being the most highly upregulated. This is consistent with the idea that pathogenic bacteria adapt to various host environments by varying the synthesis of surface components (Mekalanos, 1992). Together, these results indicate that membrane remodelling may occur in $M$. genitalium in order to cope with high-osmolarity environments. Since the majority of these induced genes are annotated as being hypothetical, their upregulation under osmotic stress implies their functionally important role in maintaining mycoplasma cellular integrity during osmotically stressful conditions in vivo. An unexpected finding is that MG_454, which encodes an osmotically inducible OsmC-like protein that is upregulated in Escherichia coli and other bacteria (Atichartpongkul et al., 2001), was downregulated (Table 3). The downregulation of MG_454 was validated by both real-time PCR (Fig. 3) and Northern blot analysis (data not shown). Although MG_454 shares sequence homology with OsmC, it is likely that transcription of MG_454 in M. genitalium is different from transcription in other bacteria given the paucity of factors involved in transcription regulation.

Cells typically accumulate osmotically active compounds referred to as compatible solutes, such as proline and glycine betaine, which are highly congruous with cellular functions that offset the deleterious effects of high osmolarity. Therefore, genes involved in the biosynthesis or uptake of compatible solutes are often induced by osmotic shock (Kempf \& Bremer, 1998). As M. genitalium relies entirely on exogenous supplies of nutrients for growth, the pathways for synthesizing compatible solutes are not easily identifiable from the genome. Interestingly, we noticed that MG_064 and MG_289, two genes encoding putative $A B C$ transporters, showed significant upregulation under osmotic shock (Table 2). MG_064 encodes a putative permease, which has been revealed to be indispensable under in vitro growth conditions (Glass et al., 2006). MG_289 was annotated as a gene encoding a putative substrate binding protein of phosphonate $A B C$ transporter, which shares sequence homology with p37 (recently designated Cypl) of Mycoplasma hyorhinis, an important factor involved in mycoplasma virulence, tumorigenic transformation and putative extracytoplasmic thiamine-binding (Sippel et al., 2009). Since SP-4 medium is enriched with amino acids that could serve as compatible solutes, it is interesting to speculate that MG_064 and MG_289 might play a role in their uptake. It remains to be investigated which substrate(s) might be transported by MG_064 and MG_289 when M. genitalium encounters osmotic stress.

Of a total of 72 genes significantly downregulated by osmotic shock, many were metabolism-related, including those involved in glycolysis ( $f b a, p g i, p g k$, gap, eno, gpml, ldh, pta, ackA, $p d h A$ and $p d h B)$. Moreover, the expression of genes involved in protein translation was also repressed, including those encoding ribosomal proteins ( $r p s P, r p l L$, $r p l S, r p l K, r p l A, r p s D$ and $r p m F$ ), translation factors (tuf and $t s f)$ and tRNA synthesis $(t r m D)$. The downregulation of these genes is consistent with the observed reduction in mycoplasma protein synthesis under osmotic shock (Fig. 1), similar to other bacteria (Weber \& Jung, 2002). We noticed that eight genes (atpA, atpB, atpC, aptD, atpE, atpF, atpG and atpH), which encode proteins involved in the formation of $\mathrm{F}_{1} / \mathrm{F}_{0}-\mathrm{ATP}$ synthase complex, were repressed as well. In most prokaryotes, the function of the $\mathrm{F}_{1} / \mathrm{F}_{0}$-ATP synthase complex is to maintain a proton gradient through catabolism and hydrolysis of ATP. Since the cytochrome-dependent electron transport chain is absent in mycoplasmas, the function of the synthase complex is believed to be to chiefly maintain the electrochemical gradient in mycoplasmas. Decreased expression of genes encoding $\mathrm{F}_{1} / \mathrm{F}_{0}-\mathrm{ATP}$ synthase was observed in the early response of $E$. coli during osmotic shock, suggesting severe inhibition of respiration (Meury, 1994; Weber \& Jung, 2002). Downregulation of four of the eight ATP synthase subunits has been observed in Mycoplasma gallisepticum when co-incubated with eukaryotic cells (Cecchini et al., 2007). The functional implication of this downregulation of $\mathrm{F}_{1} / \mathrm{F}_{0}-\mathrm{ATP}$ synthase genes in M. genitalium under osmotic stress is unknown.

Presently, we cannot explain what mechanisms regulate the differential expression of genes under osmotic shock, given the presence of only a single $\sigma$ factor in M. genitalium. However, the increased expression of genes encoding DNA gyrase ( $g y r A$ and $g y r B)$ and GTP pyrophosphokinase ( $r e l A$ ) during osmotic shock is of special interest (Table 2). DNA gyrase is involved in introducing negative supercoiling into DNA and maintaining the homeostasis of DNA topology of bacterial chromosomes together with DNA topoisomerase IV (Wang, 1996). The expression of gyrase is regulated by DNA supercoiling, which is often altered in response to environmental changes such as osmolarity and temperature, and has been identified as an important factor in globally influencing gene expression in many bacteria (Dorman, 1991). Previously, a microarray study identified a regulatory role of DNA supercoiling in controlling the osmotic stress response in E. coli (Cheung et al., 2003). Therefore, the significant induction of $g y r B$ and $g y r A$ in $M$. genitalium under $0.3 \mathrm{M} \mathrm{NaCl}$ treatment (Table 2) suggests that DNA supercoiling of the chromosome is perturbed and may be essential in regulating genes under osmotic shock. Also, MG_278 (relA; Table 2) encodes a conserved enzyme responsible for the synthesis of ppGpp, which is an important signal molecule involved in stringent response. Interestingly, the overexpression of MPN_397, a homologue of MG_278 in M. pneumoniae, leads to transcriptional changes mainly related to stringent responses, indicating that the biological conservation of this signalling mechanism occurred despite genome reduction (Yus et al., 2009). Induction of relA under osmotic shock has also been 
demonstrated in Lactococcus lactis. Moreover, the disruption of rel, a homologue of relA in Listeria monocytogenes, reduced osmotolerance, suggesting that appropriate intracellular concentrations of ppGpp are essential for full osmotolerance (Okada et al., 2002). Therefore, it appears that DNA gyrase and GTP pyrophosphokinase contribute to mechanisms of transcriptional regulation in $M$. genitalium during osmotic stress.

Another noteworthy feature of $M$. genitalium genes differentially expressed under osmotic shock is that many appear to be co-transcribed and comprise operons (Supplementary Fig. S1). For example, MG_003 and MG_004 encode two subunits of DNA gyrase ( $g y r A$ and $g y r B)$ and both are induced under osmotic shock. A similar example among downregulated genes is the gene cluster encoding $\mathrm{F}_{1} / \mathrm{F}_{0}$-ATP synthase complex $\left(\mathrm{MG}_{-} 405\right.$ to MG_398). Operon structure remains unclear in $M$. genitalium, as genes are often clustered in the same orientation with small or no intergenic spaces. Since $M$. genitalium lacks rho factor, a rho-independent transcriptional terminator is predicted to operate; so far, few have been successfully identified (Kingsford et al., 2007; Washio et al., 1998). Consequently, genes of unrelated functions could be co-transcribed due to run-on expression (Benders et al., 2005). A recent comprehensive analysis of $M$. pneumoniae transcriptomes describes the preferential use of hairpin formation to tightly regulate gene expression (Güell et al., 2009). Furthermore, operon structure seems to be dynamic and modulated by environmental changes, with the expression of genes within an operon being linked to specific environmental conditions. Therefore, further analysis of gene clusters differentially regulated under osmotic shock in M. genitalium may help define operon structure and provide hints for assigning functional roles to hypothetical genes.

In conclusion, using a DNA microarray we provide the first assessment, to our knowledge, of global transcriptional responses of M. genitalium to osmotic stress. Our data offer insights as to how M. genitalium responds to physiologically relevant environmental cues. Moreover, genes differentially expressed under osmotic shock provide candidates for further investigation of mechanisms involved in transcription regulation in M. genitalium.

\section{ACKNOWLEDGEMENTS}

This work was supported by the National Institutes of Health grant no. AI045429 and the Frost Bank Trusts. The authors are grateful to Dr Oxana Musatovova for guidance with real-time PCR and helpful discussion in preparing this manuscript.

\section{REFERENCES}

Alvarez, R. A., Blaylock, M. W. \& Baseman, J. B. (2003). Surface localized glyceraldehyde-3-phosphate dehydrogenase of Mycoplasma genitalium binds mucin. Mol Microbiol 48, 1417-1425.
Atichartpongkul, S., Loprasert, S., Vattanaviboon, P., Whangsuk, W., Helmann, J. D. \& Mongkolsuk, S. (2001). Bacterial Ohr and OsmC paralogues define two protein families with distinct functions and patterns of expression. Microbiology 147, 1775-1782.

Baseman, J. B. (1993). The cytadhesins of Mycoplasma pneumoniae and M. genitalium. Subcell Biochem 20, 243-259.

Baseman, J. B. \& Tully, J. G. (1997). Mycoplasmas: sophisticated, reemerging, and burdened by their notoriety. Emerg Infect Dis 3, 2132.

Baseman, J. B., Lange, M., Criscimagna, N., Giron, J. \& Thomas, C. (1995). Interplay between mycoplasmas and host target cells. Microb Pathog 19, 105-116.

Benders, G. A., Powell, B. C. \& Hutchison, C. A. (2005). Transcriptional analysis of the conserved fts $Z$ gene cluster in Mycoplasma genitalium and Mycoplasma pneumoniae. J Bacteriol 187, 4542-4551.

Blaylock, M. W., Musatovova, O., Baseman, J. G. \& Baseman, J. B. (2004). Determination of infectious load of Mycoplasma genitalium in clinical samples of human vaginal cells. J Clin Microbiol 42, 746-752.

Cecchini, K. R., Gorton, T. S. \& Geary, S. J. (2007). Transcriptional responses of Mycoplasma gallisepticum strain $\mathrm{R}$ in association with eukaryotic cells. J Bacteriol 189, 5803-5807.

Cheung, K. J., Badarinarayana, V., Selinger, D. W., Janse, D. \& Church, G. M. (2003). A microarray-based antibiotic screen identifies a regulatory role for supercoiling in the osmotic stress response of Escherichia coli. Genome Res 13, 206-215.

Dorman, C. J. (1991). DNA supercoiling and environmental regulation of gene expression in pathogenic bacteria. Infect Immun 59, 745-749.

Fraser, C. M., Gocayne, J. D., White, O., Adams, M. D., Clayton,, R. A., Fleischmann, R. D, Bult, C. J., Kerlavage, A. R., Sutton, G. \& other authors (1995). The minimal gene complement of Mycoplasma genitalium. Science 270, 397-403.

Glass, J. I., Assad-Garcia, N., Alperovich, N., Yooseph, S., Lewis, M. R., Maruf, M., Hutchison, C. A., Smith, H. O. \& Venter, J. C. (2006). Essential genes of a minimal bacterium. Proc Natl Acad Sci U S A 103, 425-430.

Güell, M., van Noort, V., Yus, E., Chen, W. H., Leigh-Bell, J., Michalodimitrakis, K., Yamada, T., Arumugam, M., Doerks, T. \& other authors (2009). Transcriptome complexity in a genomereduced bacterium. Science 326, 1268-1271.

Himmelreich, R., Plagens, H., Hilbert, H., Reiner, B. \& Herrmann, R. (1997). Comparative analysis of the genomes of the bacteria Mycoplasma pneumoniae and Mycoplasma genitalium. Nucleic Acids Res 25, 701-712.

Jensen, J. S. (2004). Mycoplasma genitalium: the aetiological agent of urethritis and other sexually transmitted diseases. J Eur Acad Dermatol Venereol 18, 1-11.

Kempf, B. \& Bremer, E. (1998). Uptake and synthesis of compatible solutes as microbial stress responses to high-osmolality environments. Arch Microbiol 170, 319-330.

Kingsford, C. L., Ayanbule, K. \& Salzberg, S. (2007). Rapid, accurate, computational discovery of Rho-independent transcription terminators illuminates their relationship to DNA uptake. Genome Biol 8, R22.

Madsen, M. L., Nettleton, D., Thacker, E. L., Edwards, R. \& Minion, F. C. (2006a). Transcriptional profiling of Mycoplasma hyopneumoniae during heat shock using microarrays. Infect Immun 74, 160-166.

Madsen, M. L., Nettleton, D., Thacker, E. L. \& Minion, F. C. (2006b). Transcriptional profiling of Mycoplasma hyopneumoniae during iron depletion using microarrays. Microbiology 152, 937-944. 
Madsen, M. L., Puttamreddy, S., Thacker, E. L., Carruthers, M. D. \& Minion, F. C. (2008). Transcriptome changes in Mycoplasma hyopneumoniae during infection. Infect Immun 76, 658-663.

Mekalanos, J. J. (1992). Environmental signals controlling expression of virulence determinants in bacteria. J Bacteriol 174, 1-7.

Meury, J. (1994). Immediate and transient inhibition of the respiration of Escherichia coli under hyperosmotic shock. FEMS Microbiol Lett 121, 281-286.

Musatovova, O., Dhandayuthapani, S. \& Baseman, J. B. (2006). Transcriptional heat shock response in the smallest known selfreplicating cell, Mycoplasma genitalium. J Bacteriol 188, 2845-2855.

Okada, Y., Makino, S., Tobe, T., Okada, N. \& Yamazaki, S. (2002). Cloning of rel from Listeria monocytogenes as an osmotolerance involvement gene. Appl Environ Microbiol 68, 1541-1547.

Schafer, E. R., Oneal, M. J., Madsen, M. L. \& Minion, F. C. (2007). Global transcriptional analysis of Mycoplasma hyopneumoniae following exposure to hydrogen peroxide. Microbiology 153, 3785-3790.

Sippel, K. H., Robbins, A., Reutzel, R., Boehlein, S., Namiki, K., Goodison, S., Agbandje-McKenna, M., Rosser, C. \& McKenna, R. (2009). Structural insights into the extracytoplasmic thiaminebinding lipoprotein p37 of Mycoplasma hyorhinis. J Bacteriol 191, 2585-2592.

Storey, J. D. \& Tibshirani, R. (2003). Statistical significance for genomewide studies. Proc Natl Acad Sci U S A 100, 9440-9445.
Ueno, P. M., Timenetsky, J., Centonze, V. E., Wewer, J. J., Cagle, M., Stein, M. A., Krishnan, M. \& Baseman, J. B. (2008). Interaction of Mycoplasma genitalium with host cells: evidence for nuclear localization. Microbiology 154, 3033-3041.

Wang, J. C. (1996). DNA topoisomerases. Annu Rev Biochem 65, 635692.

Washio, T., Sasayama, J. \& Tomita, M. (1998). Analysis of complete genomes suggests that many prokaryotes do not rely on hairpin formation in transcription termination. Nucleic Acids Res 26, 54565463.

Weber, A. \& Jung, K. (2002). Profiling early osmostress-dependent gene expression in Escherichia coli using DNA microarrays. J Bacteriol 184, 5502-5507.

Weiner, J., Herrmann, R. \& Browning, G. F. (2000). Transcription in Mycoplasma pneumoniae. Nucleic Acids Res 28, 4488-4496.

Weiner, J., Zimmerman, C. U., Gohlmann, H. W. H. \& Herrmann, R. (2003). Transcription profiles of the bacterium Mycoplasma pneumoniae grown at different temperatures. Nucleic Acids Res 31, 63066320.

Yus, E., Maier, T., Michalodimitrakis, K., van Noort, V., Yamada, T., Chen, W. H., Wodke, J. A., Güell, M., Martínez, S. \& other authors (2009). Impact of genome reduction on bacterial metabolism and its regulation. Science 326, 1263-1268.

Edited by: J. Renaudin 